\title{
Gemfibrozil reduced the risk for coronary events in men with coronary artery disease and low levels of high density lipoprotein cholesterol
}

Rubins HB, Robins SJ, Collins D, et al, for the Veterans Affairs High-Density Lipoprotein Cholesterol Intervention Trial Study Group. Gemfibrozil for the secondary prevention of coronary heart disease in men with low levels of high-density lipoprotein cholesterol. N Engl J Med 1999 Aug 5;341:410-18.

QUESTION: Is gemfibrozil effective for secondary prevention of coronary artery disease (CAD) events in men with low levels of both high density lipoprotein (HDL) and low density lipoprotein (LDL) cholesterol?

\section{Design}

Randomised \{allocation concealed*\},† blinded (patients, outcome assessors, and study personnel),* placebo controlled trial with median follow up of 5.1 years (Veterans Affairs High-Density Lipoprotein Cholesterol Intervention Trial [VA-HIT]).

\section{Setting}

20 Veterans Affairs medical centres in the United States.

\section{Patients}

2531 men who were $<74$ years of age (mean age $64 \mathrm{y}$ ); had a documented history of CAD; had no serious comorbid conditions; and had an HDL cholesterol level $\leq 40 \mathrm{mg} / \mathrm{dl}(1.0 \mathrm{mmol} / \mathrm{l})$, an LDL cholesterol level $\leq 140 \mathrm{mg} / \mathrm{dl}(3.6 \mathrm{mmol} / \mathrm{l})$, and a triglyceride level $\leq 300 \mathrm{mg} / \mathrm{dl}(3.4 \mathrm{mmol} / \mathrm{l})$.

\section{Intervention}

1264 men were allocated to gemfibrozil, $1200 \mathrm{mg} / \mathrm{d}$, and 1267 were allocated to placebo.

\section{Main outcome measures}

The main outcome was combined incidence of non-fatal myocardial infarction (MI) or death from CAD. Secondary outcomes included stroke and all cause mortality.

\section{Main results}

Analysis was by intention to treat. Patients in the gemfibrozil group had a lower risk for the combined end point of non-fatal MI or CAD death and for investigator designated stroke (table) than did patients in the placebo group; groups did not differ for all cause mortality $(15.7 \%$ v $17.4 \%, \mathrm{p}=0.23)$.

\section{Conclusion}

Among men with coronary artery disease and low levels of both high density and low density lipoprotein cholesterol, gemfibrozil reduced the risk for the combined end point of non-fatal myocardial infarction or death from coronary artery disease.

*See glossary.

†Information provided by author.

Gemfibrozil v placebo for secondary prevention of coronary artery disease (CAD) in men with low levels of high density lipoprotein cholesterol $\neq$

\begin{tabular}{lcccc} 
Outcomes at 5 y & Gemfibrozil & Placebo & RRR (95\% CI) & NNT (CI) \\
Non-fatal myocardial infarction or CAD death & $17.3 \%$ & $21.7 \%$ & $22 \%(7$ to 35$)$ & $23(13$ to 74$)$ \\
\hline Stroke & $5.1 \%$ & $6.9 \%$ & $29 \%(2$ to 48$)$ & $56(27$ to 725$)$ \\
\hline
\end{tabular}

$\ddagger$ Abbreviations defined in glossary; NNT and $\mathrm{Cl}$ provided by author.

\section{COMMENTARY}

The results of the VA-HIT should change practice Clinicians should no longer be complacent when patients with coronary disease have low HDL cholesterol levels ( $\leq 40 \mathrm{mg} / \mathrm{dl}$ ) as well as LDL cholesterol levels below guideline recommended thresholds for treatment. Women with lipid profiles similar to the men in this study should also benefit from treatment. The failure to show a reduction in all cause mortality is not an important weakness; the sample size was not calculated to show this reduction. A larger study would probably show this reduction, as have other studies of cholesterol lowering therapies.

An alternative strategy for this patient population is the use of statins to lower LDL cholesterol levels to 70 to $80 \mathrm{mg} / \mathrm{dl}$. In a small study of 341 patients, Pitt and colleagues $^{1}$ found that patients who had LDL cholesterol levels reduced to a mean of $77 \mathrm{mg} / \mathrm{dl}$ from about $145 \mathrm{mg} /$ $\mathrm{dl}$ with atorvastatin had fewer ischaemic events than patients treated with angioplasty and standard lipid management. The Scandinavian Simvastatin Survival Study showed a treatment benefit in patients with baseline LDL cholesterol levels of approximately $140 \mathrm{mg} / \mathrm{dl}$; notably, HDL cholesterol levels increased $8 \%$ with simvastatin. ${ }^{2}$ Whether similar benefits from statins would be found in patients with LDL cholesterol levels of approximately $110 \mathrm{mg} / \mathrm{dl}-$ the mean level in VA-HIT patients-is unknown.

When treating patients with CAD who have normal LDL and low HDL cholesterol levels, evidence for using gemfibrozil is now stronger than for using statins. If a statin is used, clinicians should check for an increase in HDL cholesterol level of $\geq 6 \%$, as seen in the VA-HIT. An alternative to medication might be weight loss and exercise if an equivalent $6 \%$ increase in HDL cholesterol levels can be achieved. Edward P Havranek, MD Denver Health Medical Center Denver, Colorado, USA

1 Pitt B, Waters D, Brown WV, et al. Aggressive lipid-lowering therapy compared with angioplasty in stable coronary artery disease. Atorvastatin versus Revascularization Treatment Investigators. N Engl J Med 1999;341:70-6.

2 Pedersen TR, Olsson AG, Faergeman O, et al. Lipoprotein changes and reduction in the incidence of major coronary heart disease events in the Scandinavian Simvastatin Survival Study (4S). Circulation 1998;97:1453-60.
Sources of funding: Veterans Affairs Office of Research and Development and Parke-Davis.

For correspondence: Dr HB Rubins, Section of General Internal Medicine (111O),

Veterans Affairs Medical Center, Minneapolis, $M N$ 55417, USA Fax +1612725 2118. 